\section{Stopping the haemorrhage from peptic ulcers}

A tenth or more of patients admitted to hospital because of bleeding from a peptic ulcer may die. The mortality has fallen over the years ${ }^{1}$ owing to improvements in the general care of the shocked patient and changes in surgical technique. ${ }^{2}$ Endoscopy soon after admission has supplanted radiography in searching for the site of the bleeding ${ }^{3}$ but enthusiasm for this approach has waned-partly because four-fifths of ulcers will stop bleeding spontaneously and do not need the urgent attention of an endoscopist. Another reason is evidence from controlled trials of the failure of early and accurate endoscopic assessment to affect the proportion of patients who require surgery or to alter the death rate from bleeding. ${ }^{4}$

These disappointing results indicate our relative inability to prevent rebleeding and the difficulties facing us when we try to staunch persisting or recurrent bleeding. Other carefully controlled trials have shown that cimetidine offers no benefit in these contexts. ${ }^{6} 7$ Somatostatin, a new compound which inhibits gastrin release, inhibits the secretion of gastric acid, and reduces the blood flow in the coeliac axis, has not yet had a proper trial to determine its effect on bleeding. ${ }^{8}$

If we cannot give drugs to stop the ulcer bleeding what more direct action can be taken ? Surgery is the surest means, but as many as a third of patients operated on because of bleeding may die after surgery (though some centres ${ }^{9}$ are now recording mortality rates as low as $3 \%$ ). The two prime reasons for the high surgical mortality are that, firstly, many of the patients are old and unfit before they bleed; while, secondly, their prospects are often further impaired by inadequate treatment of the blood loss and its complications. Too often surgery is undertaken at the eleventh hour. A direct attack on the bleeding point by less invasive means than surgery would be expected to reduce the mortality if it could reliably stop the bleeding. To this end several angiographic and endoscopic techniques are under trial.

If the bleeding point can be identified by angiography and a catheter introduced into the vessel feeding that point then haemostasis can be attempted either by infusing vasopressin or by occluding the vessel with emboli introduced through the catheter. Both techniques require a skilled angiographer, and both have hazards.

Vasopressin controls bleeding in only a minority of patients, and in only a quarter is the control long term. ${ }^{10}$ Embolisation seems to have been more successful. Reuter, for example, has reported on 40 successful procedures, ${ }^{11}$ but no controlled trial of the method has yet been reported, and serious complications may result from infarction of surrounding organs. ${ }^{12} 13$

An alternative approach is through the flexible endoscope. Attempts at sealing off the bleeding point by this route by using cyanoacrylic glue have failed experimentally. ${ }^{14}$ The direct spraying of clotting factors on to the site of haemorrhage has been effective in dogs ${ }^{15}$ but is unlikely to be of value for very brisk haemorrhage. Electrocautery or laser beam might be expected to give more effective haemostasis.

Several reports of large series show good initial control of haemorrhage by electrocautery, with a low incidence of rebleeding, ${ }^{16}{ }^{17}$ but the results of randomised trials have not yet been published. Electrocautery damages the tissues around the bleeding point and may even worsen haemorrhage. In contrast, the blue-green light of the argon laser is selectively absorbed by blood and can produce local coagulation with minimal damage to surrounding tissues-but the technique requires special and expensive apparatus. Two controlled trials have been reported. The first, by Vallon et al, was based on 136 patients seen on endoscopy to be actively bleeding or to have bled recently. ${ }^{18}$ They were randomised into two groups: in half the ulcer was photocoagulated and the other group received only supportive treatment. No differences were found between the groups when rebleeding, death, or the need for surgery was reviewed. The other trial ${ }^{20}$ randomised 76 patients and claimed to show a lower incidence of rebleeding and death in patients found on endoscopy to have a vessel visible in the ulcer. The statistical validity of this claim has been challenged, ${ }^{21}$ and while controlled studies must continue the Argon laser must for the present be considered of unproved value. A preliminary report on a controlled study of the Nd YAG laser showed that it reduced the incidence of rebleeding but did not affect the mortality rate. ${ }^{22}$

The likelihood that bleeding from a peptic ulcer will stop spontaneously is so high that no technique for stopping the haemorrhage can be judged clinically useful unless validated by a controlled trial. Because of the large numbers of patients needed for such trials few have been done-and there is no evidence that justifies widespread adoption of any of these new techniques for attempting to stop continuing haemorrhage. They are, in general, time-consuming procedures, and if they fail they may merely have delayed more conventional treatment. Furthermore, neither angiography nor endoscopy is a procedure that is free of complications.

The ordinary clinician managing persisting haemorrhage must pin his hopes not on modern technological advances but on efficient and prompt replacement of blood loss, early feeding, ${ }^{23}$ and skill in judging the appropriate moment for surgical intervention. ${ }^{9}$

A E Young

Consultant surgeon,

St Thomas's Hospital,

London SE1 7EH

${ }^{1}$ Bernvai J, Novel O, Belghiti J, Rueff B. Severe upper Gastrointestinal bleeding: guidelines for treatment. Clin Gastroenterol 1981;10:38-59.

${ }^{2}$ Grime RT. Gastroduodenal haemorrhage. Ann R Coll Surg Engl 1979;61: 123-31.

3 Theoni RF, Cello JP. A critical look at the accuracy of endoscopy and double-contrast radiography of the upper gastrointestinal (UGI) tract in patients with substantial UGI hemorrhage. Radiology 1980;135:305-11.

4 Graham DY. The value of endoscopy in the management of acute upper gastrointestinal bleeding: a prospective controlled randomised study. Gastroenterology 1978;74:1125.

${ }^{5}$ Peterson WL, Barnett CC, Smith HJ, Allen MH, Corbett DB. Routine early endoscopy in upper-gastrointestinal-tract bleeding; a randomised, controlled trial. N Engl f Med 1981 ;304:925-9.

${ }^{6}$ Pickard RG, Sanderson I, South M, Kirkham JS, Northfield TC. Controlled trial of cimetidine in acute upper gastrointestinal bleeding. Br Med f 1979;i:661-2.

7 La Brooy SJ, Misiewicz JJ, Edwards J, et al. Controlled trial of cimetidine in upper gastrointestinal haemorrhage. Gut 1979;20:892-5.

${ }^{8}$ Kayassah L, Gyr K, Keller V, Stalder GA, Wall M. Somatostatin and cimetidine in peptic ulcer haemorrhage. Lancet 1980;i:844-6.

${ }^{9}$ Hunt PS, Korman MG, Hansky J, Marshall RD, Peck GS, McCann WJ. Bleeding duodenal ulcer. Reduction in mortality with a planned approach. Br F Surg 1979;66:633-5.

${ }^{10}$ Johnson WC, Widrich WC. Efficacy of selective splanchnic arteriography and vasopressin perfusion in diagnosis and treatment of gastrointestinal hemorrhage. Am 7 Surg 1976;131:481-9.

11 Reuter SR. Embolisation of gastrointestinal hemorrhage. $A f R \quad 1979 ; 133$ : $557-8$.

12 Shapiro N, Brandt L, Sprayregan S, Mitsudo S, Glotzer P. Duodenal infarction after therapeutic Gelfoam embolisation of a bleeding duodenal ulcer. Gastroenterology $1981 ; 80: 176-80$.

13 Page C. Discussant in Matolo N, Link DP. Selective embolisation for control of gastrointestinal hemorrhage. Am f Surg 1979;138:840-4.

14 Protell RL, Silverstein FE, Gulacsik C, Martin TR, Ovm D, Rubin CE. Failure of cyanoacrylate tissue glue (flucrylate, MBR 4197) to stop bleeding from experimental canine gastric ulcers. Am 7 Dig Dis 1978 ;23 : 903-8.

${ }^{15}$ Linscheer WG, Fazio TL. Control of upper gastrointestinal hemorrhage by endoscopic spraying of clotting factors. Gastroenterology 1979;77: 642-6. 
${ }^{16}$ Wara P, Höjsgaard A, Amdrup R. Endoscopic electrocoagulation-an alternative to operative hemostasis in active gastroduodenal bleeding ? Endoscopy 1980;12:237-40.

17 Gaisford WD. Endoscopic electrohemostasis of active gastrointestinal bleeding. Am F Surg 1979;137:47-53.

18 Vallon AG, Cotton PB, Laurence BH, Miro JRA, Oses JCS. Randomised trial of endoscopic argon laser photocoagulation in bleeding peptic ulcers. Gut $1981 ; 22: 228-33$.

19 Cotton PB. Problems for emergency endoscopic treatment of upper gastrointestinal bleeding. Clin Gastroenterol $1981 ; 10: 59-64$.

20 Swain CB, Bown SG, Storey DW, Kirkham JS, Northfield TC, Salmon $\mathrm{PR}$. Controlled trial of argon laser photocoagulation in bleeding peptic ulcers. Lancet 1981 ;ii:1313-6.

${ }^{21}$ Henry DA, Langman MJS. Argon laser photocoagulation in bleeding peptic ulcers. Lancet $1982 ; \mathrm{i}: 99$.

22 Vantrappen G, Rutgeerts P, Broeckaert L, Janssens J, Coremans G. Controlled trial of neodymium YAG laser treatment for upper digestive haemorrhage. Gastrointestinal Endoscopy $1981 ; 27: 139$ (abstract).

${ }^{23}$ Anonymous. Management of gastrointestinal bleeding. Br Med $\mathcal{f} 1981$; 283 :456-7.

\section{Recurrent cancer after restorative resection of the rectum}

As more surgeons have come to use mechanical staplers they are also beginning to question the need for permanent colostomy with total resection of the rectum as the usual treatment for many cancers in this part of the bowel. ${ }^{12}$ Despite the known high incidence of local recurrence after both abdominoperineal resections and restorative anterior resections of the rectum stapling is becoming more popular. There are considerable discrepancies, as much as tenfold, in the reported incidences of recurrences after resections of rectal cancer, probably owing to the obvious difficulties of detection in the pelvis. The only method of resolving these uncertainties would be the impractical one of routine necropsies. We may be sure, however, that most reports of recurrences underestimate the true incidence.

The importance of the problem was realised many years ago by Miles ${ }^{3}$ during the development of abdominoperineal excision of the rectum, and not only does the issue remain as clamant today but it is also likely to become more frequent with the rising tendency to consider restorative resections. Even in centres with the lowest incidences of around $10 \%$ local recurrences sometimes develop in patients with early (Dukes's grade A) cancers. In the series reported by Goligher et $a l,{ }^{4}$ however, and in many others which included both abdominoperineal and anterior resections local recurrences were most frequent after the removal of Dukes's grade C cancers and those situated in the lower half of the rectum. At least onethird $^{5}$ and sometimes as many as one-half ${ }^{6}$ of patients with Dukes's grade B or grade C cancers of the rectum developed local recurrences.

Radiotherapy prescribed either before or after resection has been used with good effect on the local recurrence rates in some trials. Preoperative low-dose regimens appear to yield results which are not improved by higher doses, but this point needs to be critically tested. Systemic chemotherapy, as intravenous 5-fluorouracil for some months after resection, has resulted in apparently increased disease-free intervals in treated patients. ${ }^{7}$ In a current multicentre randomised trial organised from the National Cancer Institute in the United States of America there are four treatment groups: surgery alone, surgery with additional postoperative radiotherapy, surgery with additional chemotherapy, and surgery with both. All patients had spread of cancer to the regional lymph nodes or penetration of the bowel wall. Postoperative radiotherapy was given for about five weeks, and chemotherapy (5-fluorouracil and CCNU) was continued for 18 months. A preliminary assessment after two and a half years of follow-up showed that only $21 \%$ of patients receiving all three treatments had had local or distant recurrences-less than half the incidence of $52 \%$ among those treated by rectal excision alone. Just local recurrence was seen in only $3 \%$ of those given three treatments and in $19 \%$ of those treated by surgery alone.

Topical chemotherapy by the instillation of mercuric perchloride into the isolated distal stump of the rectum has been widely used for many years ${ }^{8}$ and is thought to limit the incidence of local recurrence.

The current consensus seems to be that a combination of chemotherapy, both systemic and topical, plus irradiation, either preoperative or postoperative, should be used whenever restorative surgery is contemplated, particularly for the highrisk Dukes's grade C cancers and for those occurring in the lower half of the rectum. One problem is that rectal cancers cannot be staged accurately before they are excised; all patients should therefore receive multimodal treatment. A pilot study of 12 patients followed up for up to six years after a regimen of this type $^{9}$ showed an anastomotic leak, detected radiologically, in only one case and no evidence of local recurrence. Preoperative radiation can be expected to arrest the growth of cancer cells in the rectal wall and in pararectal lymphatic and other tissues. Intraoperative topical chemotherapy should eliminate exfoliated intrarectal cancer cells and the agents may also permeate the pararectal tissues. Thus the two main sources of locally recurrent cancer are attacked and some protection should be afforded against the known high risk accompanying restorative resections. These considerations-and the absence of anastomotic leakage in large series using preoperative radiotherapy but not chemotherapy ${ }^{1011}$ before conventional anterior resections of the rectum-show that multimodal chemoradiotherapeutic treatments adjuvant to restorative resections for rectal cancers should be subjected to the rigour of controlled clinical measurement and comparison with radiotherapy alone and with chemotherapy alone.

Though improved survival has not been shown after all these regimens, reduced local recurrence itself justifies widespread application of the multimodal approach. Patients should not be rushed to the operating theatre within a few days of diagnosis. The characteristics of the cancer should be thoroughly defined locally and searches made biochemically and radiologically for distant metastases. Consultation between radiotherapist and surgeon should then resolve which multimodal regimen will serve each patient best. Ideally most patients should be entered into controlled trials testing specific questions whose solutions might benefit present and future patients. Unfortunately adequate trial organisations have not developed in Britain; nevertheless, the single randomised trial, organised by the Medical Research Council, has acquired 849 patients in three years for comparison of two regimens of preoperative radiotherapy and non-irradiated controls. The definitive follow-up results are awaited; meanwhile the high incidence and poor outcome of colorectal cancers are clear indications that this is a problematic area which should be given priority.

\section{JoHn MAXWELl. ANDERSON}

Consultant Surgeon,

Royal Infirmary,

Glasgow G4 OSF 